\begin{tabular}{|c|l|}
\hline Title & Hypokalemic coma with tetany following pseudo-Bartter syndrome. \\
\hline Author(s) & Hayakawa, Mineji; Gando, Satoshi; Morimoto, Y uji; Takey ama, Y osihiro; Sato, Tomoyuki; Matubara, Izumi \\
\hline Citation & $\begin{array}{l}\text { Intensive care medicine, 26(11), 1711 } \\
\text { https://doi.org/10.1007/3001340000688 }\end{array}$ \\
\hline Issue Date & 2000-11 \\
\hline Doc URL & http://hdl.handle.net/2115/45377 \\
\hline Rights & The original publication is available at www.springerlink.com \\
\hline Type & article (author version) \\
\hline File Information & ICM26-11_1711.pdf \\
\hline
\end{tabular}

Instructions for use 


\title{
Hypokalemic coma with tetany following pseudo-Bartter syndrome
}

\author{
Mineji Hayakawa, MD \\ Satoshi Gando, $\mathrm{MD}, \mathrm{PhD}^{*}$ \\ Yuji Morimoto, $\mathrm{MD}, \mathrm{PhD}^{*}$ \\ Yosihiro Takeyama, MD \\ Tomoyuki Sato, MD \\ Izumi Matubara, MD, $\mathrm{PhD}$ \\ Department of Emergency and Critical Care Medicine, \\ Sapporo City General Hospital, N11 W13, Chuou-Ku, \\ Sapporo, 060 - 8604 Japan \\ *Department of Anesthesiology and Critical Care Medicine, \\ Hokkaido University Graduate School of Medicine, N17 W5, Kita-ku, \\ Sapporo, 060-8648 Japan
}

Corresponding author: Mineji Hayakawa, MD Department of Emergency and Critical Care Medicine, Sapporo City General Hospital, N11 W13, Chuou-Ku, Sapporo, 060 - 8604 Japan

Tel : +81-11-726-2211, Fax : +81-11-726-7912 e-mail :mineji@dm.mbn.or.jp

No financial support was provided for this study.

This manuscript contains 397 words. 
Key words

Hypokalemia

Coma

Pseudo-Bartter syndrome 
Sir: Hypokalemia is one of the most clinically important of the electrolyte abnormalities, since it can produce a serious and potentially life-threatening condition. We describe a rare case of a hypokalemic patient in whom the outstanding clinical problems were coma and tetany.

A 36-year-old woman complained of chest discomfort and requested emergency medical service. When the patient was admitted to our emergency room, she was in a deep coma and had tetany in all extremities. She could not open her eyes or vocalize, and she did not respond to pain. No arrhythmia was observed on her electrocardiogram. Arterial blood gas analysis revealed $\mathrm{pH}$ 7.514, $\mathrm{PaCO}_{2} 6.5 \mathrm{kPa}, \mathrm{PaO}_{2} 10.5 \mathrm{kPa}$, base excess 13.6mmol/l, Na 134.9, K 2.25, Ca 1.05, and Cl 89mmol/l. After calcium chloride and magnesium sulfate were administered intravenously, the tetany disappeared, but her consciousness did not show remarkable change. Her brain computed tomography was normal. With the continuous infusion of potassium chloride, her consciousness gradually improved. The patient was almost alert 6 hours after the start of potassium chloride infusion. The serum potassium was increased to $3.24 \mathrm{mmol} / \mathrm{l}$ at that time. Later, it was found that she had been suffering from pseudo-Bartter syndrome for a few years.

This clinical course suggests that coma was closely linked with 
hypokalemia. Her consciousness recovered quickly in association with the increase of serum potassium from $2.25 \mathrm{mmol} / \mathrm{l}$ to $3.24 \mathrm{mmol} / \mathrm{l}$. Several consequences of hypokalemia are well recognized. However, only a few cases of consciousness disorder following hypokalemia have been reported [1,2]. The pathophysiological mechanisms of the hypokalemic coma are unclear. Changes in transmembrane potential or inhibition of intracellular enzyme following intra-cellular potassium depletion have been suggested as mechanisms [2]. In the present case, hypokalemia occurred in association with pseudo-Bartter syndrome. Although anorexia nervosa, diuretic abuse, or chronic vomiting is each a well-known cause of pseudo-Bartter syndrome, we could not find such mechanisms in our case. The severe tetany was observed in all her extremities upon admission to our emergency room. The tetany was caused by hypokalemic alkalosis following pseudo-Bartter syndrome. Although the tetany disappeared after the administration of calcium and magnesium, the coma did not improve, which suggests that the tetany was not involved as the pathophysiologic cause of her unconsciousness.

Although hypokalemic coma is very rare, it is important as a cause of consciousness disorder. When we encounter unconscious patients with hypokalemia, we should keep in mind the possibility of hypokalemic coma. 


\section{References}

1. Aizaki T, Osaka M, Hara H, Kurokawa S, Matsuyama K, Aoyama N, Soma K, Ohwada T, Izumi T (1999) Hypokalemia with syncope caused by habitual drinking of oolong tea. Intern Med 38: 252-256

2. Phelan DM, Worthley LI (1985) Hypokalaemic coma. Intensive Care Med 11: 257-258 